\title{
Rationale of the quantity of soil-cutting stars and working body of soil rotary knives
}

\author{
Abdulkhay Obidov $^{1 *}$, Mamaraym Turakulov², Valijon Ermatov ${ }^{2}$, and Abdurakhmon \\ Yusufaliev $^{2}$ \\ ${ }^{1}$ Tashkent State Agrarian University, 100140 Tashkent province, Uzbekistan \\ ${ }^{2}$ Gulistan State University, Gulistan, Syrdarya province, Uzbekistan
}

\begin{abstract}
This article considers the main parameters of the experimental rotary working body (RWB) used for tillage and opening of buried vines in the protection zone between rows, soil loosening and weeding blades in the protection zone of the crop protection zone, as well as the number of paddles for opening buried vines. The performance indicators of the rotary working body largely depend on its kinematic mode of operation, the number of knives, dumps and soil picks. The destruction of weeds and loosening of the soil in the root zone and the movement of the required volume of soil towards the row spacing is provided at $\lambda=1.6-1.8$ and $Z_{n}=$ $\mathrm{Z}_{\mathrm{h}}=8$ pcs.
\end{abstract}

\section{Introduction}

One of the technical solutions for the effective use of tractors on soils with low bearing capacity is the use of caterpillar propellers with a large supporting surface and better traction and coupling properties in comparison with the wheel [1].

It has been classically established that the tangential thrust force of the propeller is determined by the sum of two components: the force realized by the stubborn surfaces of the soil lugs and the friction force of the tops of the soil lugs and soil "bricks" trapped between them during slipping [1,2]. The sliding of the caterpillar propeller gives grounds to assert that the distribution of soil reactions to the pore surface of the soil tractors is uneven and depends on the traction force and working conditions. Then the slipping of the caterpillar propeller can be represented as a pulsating, jerky movement of the tractor backward at the moment of disengagement with the soil of the rear star. The soil pick, plunging into the soil, moves forward or backward, depending on the hook load, the condition of the soil and the design parameters of the pick. In this case, the persistent surface of the star track is under maximum stress, and the front surface is completely or partially unloaded $[3,4]$. The destruction of the top layer of the soil with which the soil hook interacts due to the displacement of the link of the caterpillar from the action of the adhesion force occurs.

\footnotetext{
* Corresponding author: a.a.obidov@yandex.com
} 
For each link of the caterpillar propeller during its interaction with the soil, the relationship between the reaction force and the magnitude of the link displacement will have the same character [4].

The rotary working body has already become widely used in soil cultivation in the row spacing for loosening the soil, destroying weeds and moving the soil from one side to the other in the row spacing $[4,5]$.

A rotary working body in inter-row cultivation is valued for the fact that it works with minimal deformation on the cultivated soil layers, effective loosening and achieve maximum weed control in the protective zone of the row of plants. The working bodies of the tillage implements have a variety of designs [3-5].

A feature of the rotary working body is that the zone of tillage with a knife and a soil hook depends on the trajectory of their movement. Since when the trajectories of neighboring knives overlap, the energy consumption for cutting the soil increases, then to a first approximation the number of knives and stars is determined from the condition of touching the trajectories of the adjacent knives (Fig. 1) [6-9].

Let us assume that the distance of the installation of the stars 2 from the center of rotation of the working body will slightly increase the three stars simultaneously penetrate into the covering shaft [10-12]. With such an arrangement, additional lateral force is required so that the rollback and 2 pivots penetrate into the cover shaft. This leads to the breaking of the working body, since the stars balance each other [12-15].

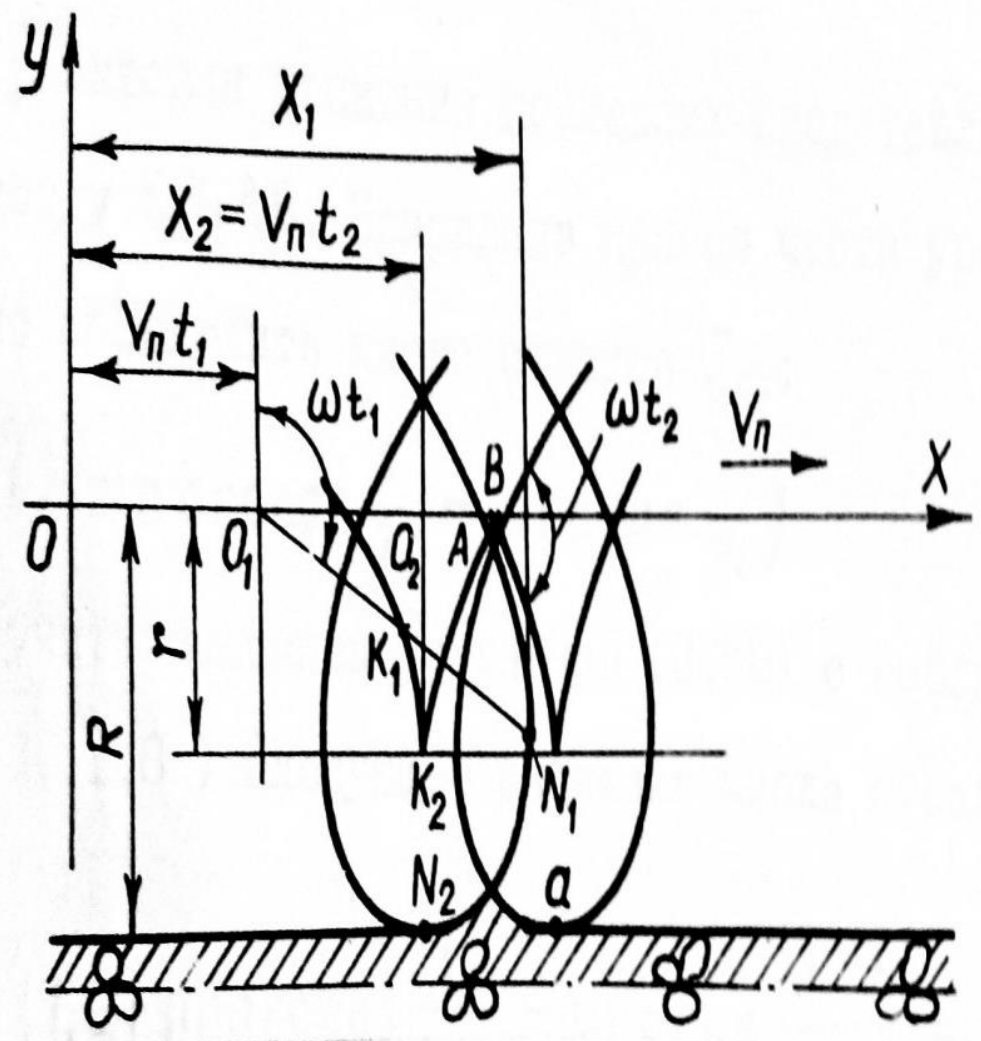

Fig 1. Scheme for determining the number of knives and stars. 


\section{Materials and methods}

Studies have shown that under the same soil conditions, with an increase in the adhesion force, the displacement (deformation) of the soil increases and, as a consequence, the destruction of its upper bearing layer [15-17]. The magnitude of the traction force and the destruction of the soil primarily depend on the design of the soil links. Soils, penetrating into the soil, create stress fields, the distribution of which determines the volume of soil deformation and the magnitude of the tangential traction force. By changing the shape and location of the soil lugs, it is possible to improve their adhesion to the soil, forming a deformed volume in such a way that the shear stress distribution fields cover as large a volume of soil as possible [17].

Half the width of the zone treated with one knife can be determined as the difference between the abscissas of the point of contact of the trajectories of the $\mathrm{N}_{1}$ knives and the point $\mathrm{N}_{2}$ of the plant as close as possible to the row line (Equations 1 and 2) [12-17]:

where,

$$
\mathrm{S} / 2=\mathrm{X} 1-\mathrm{X} 2
$$

$$
\mathrm{X} 1=\mathrm{Vn} t 1+\mathrm{R} \sin \omega t ; \quad \mathrm{X} 2=\mathrm{Vn} t 1
$$

The angles of rotation of the working body at points $\mathrm{N}_{1}$ and $\mathrm{N}_{2}$ are (Equation 3):

$$
\omega t 1=\pi / 2+\arcsin (\mathrm{r} / \mathrm{R}) ; \quad \omega t 2=\pi
$$

Then the time intervals during which the working body can rotate through the angle $\omega t_{1}$ and $\omega t_{2}$ can be determined from the expressions (Equation 4):

$$
t 1=[\pi / 2+\arcsin (\mathrm{r} / \mathrm{R})] \omega ; \quad t 2=\pi / \omega
$$

By putting in (1) the value (2), (3), (4), you can determine the width of the processing zone with one knife:

$$
\mathrm{S}=2 \mathrm{R} \sin \omega t-2 \mathrm{R} / \lambda(\pi-\omega t)
$$

On the other hand, the processing width is determined by Equation 6 [1, 3-5]:

$$
\mathrm{S}=2 \pi \mathrm{R} / \mathrm{Zh}-\lambda
$$

where, $Z_{h}$ - number of knives of the working body.

\section{Results and discussion}

In this case, the radius of the circle of the instantaneous center of rotation of the working body is the radius of the circumference of the fastening of the soil pins $r_{n}$. The trajectory of the latter is a shortened cycloid $\mathrm{K}_{1}, \mathrm{~K}_{2}$ and $\mathrm{AB}$. Equating the right-hand sides of equations (5) and (6), we can determine the number of knives $Z_{n}$ (Equation 7):

$$
\mathrm{Zh}=\pi /(\lambda \sin \arccos 1 / \lambda-\arccos 1 / \lambda)
$$

It is possible to obtain the solution of equation (4) subject to the condition $(\lambda=1.6-1.8)$ the following value of the number of knives (Equation 8): 
We accept as $Z_{h}=Z_{n}$

In order for the working body to work stably (without jerking and slipping), the number of stars must be equal to the number of knives:

$$
\mathrm{Zh}=\mathrm{Zn}
$$

And also, the number of stars and dumps of the rotary working body for opening vineyards is based on the condition that rotation is excluded.

The lower limit of the number of soil hooks can be considered as such, in which one soil hook is located inside the furrow wall, and the other begins to enter the soil. In this case, it will always adhere to the soil $[6,15]$ (Fig. 2).

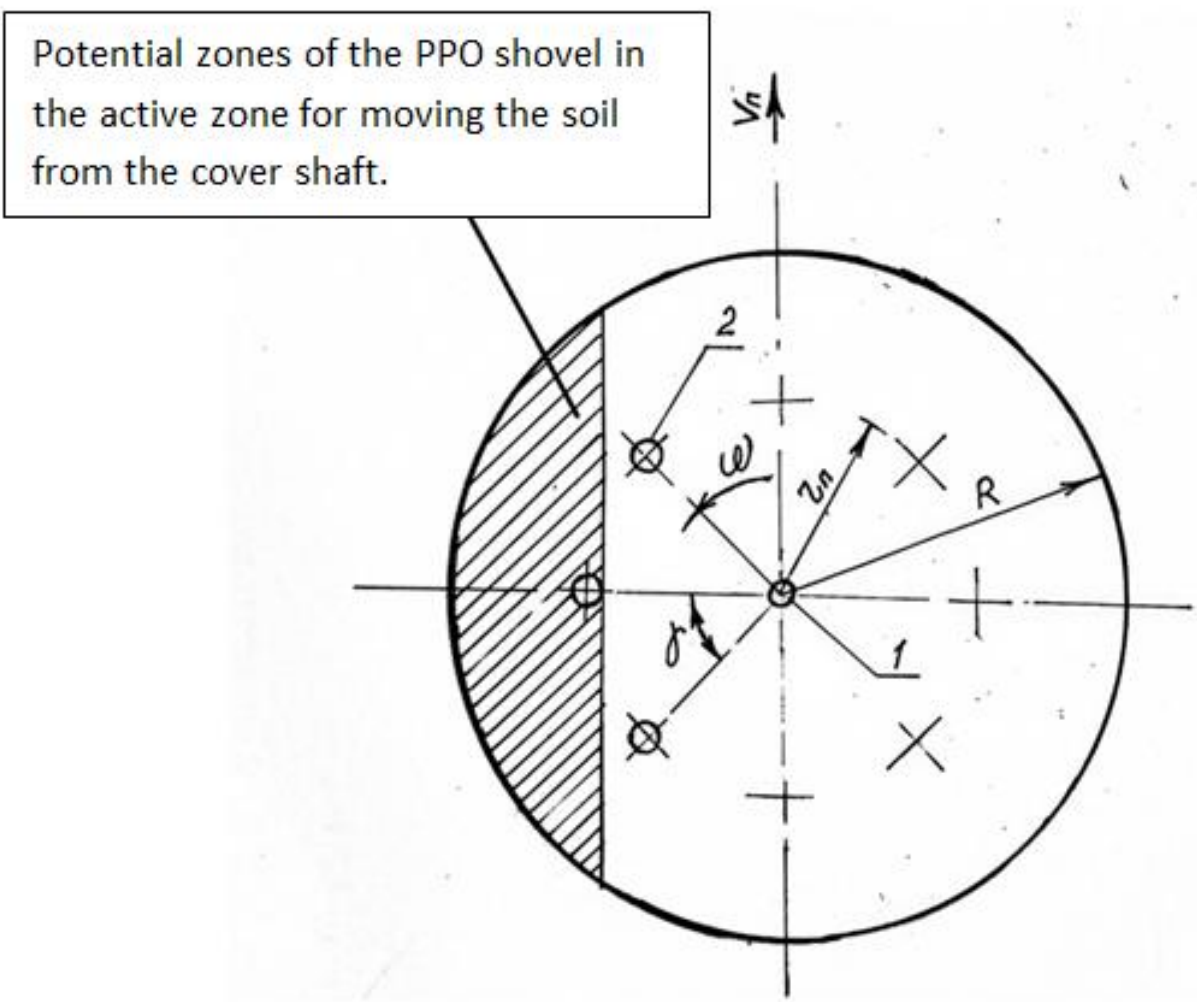

Fig. 2. Scheme for determining the distance $r_{p}$ of the installation of the stars from the center of rotation.

According to Figure 2, the number of stars can be determined through the following Equation 9:

$$
\mathrm{Zn}=2 \pi / \gamma
$$

where, $\gamma$ - central angle between the radii drawn through adjacent stars.

Angle $\gamma$ from Fig. 2 can be seen as $45^{\circ}$. 
To increase the adhesion of the blade to the soil and before sliding rotation, it is necessary that one starter is inside the cover shaft. Taking all this into account, the optimal distance of the installation of the pivots 2 from the center of rotation was chosen equal to $\mathrm{R}$ $>r_{n}>\mathrm{R} / 2$, where $\mathrm{R}$ is the radius of the outer diameter of the working body.

Substituting the value of $\gamma$ into Equation 9, we derive the number of stars:

$$
\mathrm{Zn}=2 \times 180 \mathrm{o} / 45 \mathrm{o}=360 \mathrm{o} / 45 \mathrm{o}=8
$$

\section{Conclusions}

The performance indicators of the rotary working body largely depend on its kinematic mode of operation, the number of knives, dumps and soil picks. The destruction of weeds and loosening of the soil in the root zone and the movement of the required volume of soil towards the row spacing is provided at $\lambda=1.6-1.8$ and $Z_{n}=Z_{h}=8$ pcs.

As a result of the experimental studies, it was found that eight stars fixed under the disk at a distance from the center of rotation equal to $\mathrm{R}>r_{n}>\mathrm{R} / 2$ created an additional moment, which caused the rotation of the rotary working body with minimal sliding and slipping, and also made it possible to increase the removal of soil from the covering zone.

\section{References}

1. F. M. Kanarev, Mechanical engineering, 140 (1983)

2. G. N. Sineokov, I. M. Panov, Mechanical engineering, 328 (1977)

3. V. Melikhov, V. Yuzbashev, Mechanization and Electrification of Socialist Agriculture, 2, 20-22 (1977)

4. V. A. Yuzbashev, Studying the interaction of rotary working bodies with previously loosened soil, 78, 43-48 (1994)

5. V. S. Rynkevich, Investigation of the nature of soil deformation during deep cutting with a knife in a vertical plane, 87, 17-26 (1997)

6. V. N. Tkachev, Mechanical engineering, 9, 5-17 (2001)

7. V. V. Usov, V. G. Ivashchenko, Mechanical engineering, 7, 40-68 (2000)

8. I. S. Sinyagovskiy, Strength of materials, 152-203 (1998)

9. A. A. Akhmetov, M. A. Allanazarov, Mechanization of cotton growing, 10, 4-5 (2010)

10. N. Ch. Namozov, D. A. Kodirova, M. I. Usmonova, International journal of scientific \& technology research, 9(03), 5491-5493 (2020)

11. S. Islamov, N. Namozov, M. Saidova, D. Kodirova, In E3S Web of Conferences, 244, 03028 (2021)

12. B. Abdullaev, R. A. Kulmatov, A. A. Kist, Industrial Laboratory (USSR) (English translation of Zavodskaya Laboratoriya), 54(7), 710-713 (1989)

13. N. Kulmetov, I. Gorlova, Mechanization of Cotton Research, 11, 10 (2009)

14. I. Gorlova, Mechanization of Cotton Research, 8, 12 (2010)

15. I. Gorlova, Mechanization of Cotton Research, 10, 13-14 (2013)

16. J. M. Bennett, N. P. Woodhouse, T. Keller, T. A. Jensen, D. L. Antille, Journal of Cotton Science, 19(2), 225-249 (2015)

17. W. B. Faulkner, J. D. Wanjura, R. K. Boman, B. W. Shaw, C. B. Parnell, Applied Engineering in Agriculture, 27(4), 497-506 (2011) 